\title{
Serviços clássicos na restauração comercial: proposta de padronização e esclarecimentos para futuras pesquisas
}

\author{
Classical table services in commercial catering: standardization \\ proposal and clarifications for future researches
}

\author{
Servicios clásicos de restaurantes comercial: propuesta de \\ normalización y direcciones para la investigación futura
}

\section{Rodolfo Wendhausen Krause ${ }^{1}$ Álvaro Augusto Dealcides Silveira Moutinho Bahls ${ }^{2}$}

\begin{abstract}
Resumo: Esse estudo tem como objetivo principal sintetizar os conhecimentos científicos do referencial teórico com os conhecimentos empíricos dos autores desse presente artigo sobre os quatro principais tipos/estilos de serviços individuais em estabelecimentos gastronômicos de serviço completo. Além disso busca-se, como objetivos secundários, simplificar e padronizar os tipos de serviços clássicos em restauração. Esses objetivos foram cumpridos através de uma abordagem metodológica positivista. Teve como técnicas de pesquisa uma análise comparativa e síntese do estado da arte sobre a tipologia de serviços clássica com os conhecimentos empíricos dos autores. Posteriormente, foi feita a validação da proposta de padronização por parte de um painel de avaliadores. Chegou-se a simplificação dos serviços em três categorias básicas: o serviço à francesa, à inglesa direto e serviço empratado. Entende-se que, por tratar-se de um estudo exploratório, a referida proposta é o inicia da pesquisa cientifica sobre o tema, tendo de ser averiguada com maior profundidade em estudos posteriores. 0 campo de pesquisa referente ao mise en place mostra-se, consequentemente, o que mais carece de pesquisas dessa natureza.
\end{abstract}

Palavras-chave: Restauração. Tipos de serviços. Gastronomia.

Abstract: This study aims to synthesize the scientific knowledge with the empirical knowledge of the authors of this article on the four main types/styles of individual services in gastronomic full service establishments. In addition, it seeks to, as secondary objectives, to simplify and standardize the types of classic services in restaurants. These objectives were met through a positivist methodological approach. It had as research techniques a comparative analysis and synthesis of the state of the art on the typology of classical services with the empirical knowledge of the authors. Subsequently, the validation of standardization proposal was made by a panel of evaluators. We came to simplify the services into three basic categories: French Service; Direct English Service and Platted Service. It is understood that, because it is an exploratory study, the proposal is the beginning of scientific research on the subject. Therefore, it has to be investigated in greater depth in future studies. Therefore, the research field of the mise en place is the area that greater needs research of this nature.

1 Universidade do Vale do Itajaí (UNIVALI). Balneário Camboriú,SC, Brasil

2 Universidade do Vale do Itajaí (UNIVALI). Balneário Camboriú,SC, Brasil 
Keywords: Restoration. Types of services. Gastronomy.

Resumen: Este estudio pretende resumir el conocimiento científico de lo teórico con el conocimiento empírico de los autores de este artículo sobre los cuatro principales tipos/estilos de los distintos servicios en los establecimientos gastronómicos de servicio completo. Además, se busca, como objetivos secundarios, simplificar y estandarizar los tipos de servicios clásicos de la restauración. Estos objetivos se cumplen a través de un enfoque metodológico positivista. Tenían como técnicas de investigación un análisis comparativo y la síntesis del estado del arte sobre la tipología de los servicios clásicos con el conocimiento empírico de los autores. Posteriormente, la validación de la propuesta de normalización fue realizada por un panel de evaluadores. Llegamos a simplificar los servicios en tres categorías básicas: el servicio a la francesa, el inglés directo y el servicio plateado. Se entiende que, debido a que es un estudio exploratorio, la propuesta es el comienzo de la investigación científica sobre el tema tuvo que ser investigado con mayor profundidad en futuros estudios. Se muestra el campo de la investigación para la puesta en su lugar, por lo tanto, lo que la investigación más necesidades de esta naturaleza.

Palabras clave: Restaurante. Tipos de servicios. Gastronomía.

\section{INTRODUÇÃO}

Nunca é redundante validar a importância que a alimentação possui para o ser humano, em suas mais diversas esferas, desde o suprimento de suas necessidades fisiológicas até seus desejos mais hedonistas e artísticos. $O$ ato de se alimentar e as constantes evoluções desse processo andam lado a lado com os grandes saltos evolucionários do ser humano. A evolução de nossos hábitos alimentares "levou ao aperfeiçoamento das relações sociais e econômicas, [uma das bases] para o surgimento dos deslocamentos entre os diversos grupos e suas regiões de habitação", (Krause \& Bahls, p. 434, 2016). A gastronomia como atrativo turístico somente começa a se apresentar como campo de estudos dentro das ciências sociais aplicadas muito recentemente, como "uma resposta à necessidade urgente por pesquisas que avaliem performances, identifique inadequações, eficiências e potenciais melhoramentos" (Scarpato, p. 51, 2004). Contemporaneamente, a gastronomia ultrapassa a simples esfera de atrativo turístico, sendo considerada como parte essencial do turismo, compondo, junto com a hospedagem e transporte, um trinômio inseparável (Krause \& Bahls, 2016). Portanto, a abordagem do conceito de qualidade é inerente a essa nova área de pesquisa. Haja vista que, anteriormente a qualidade era considerada um diferencial, atualmente é vista como essencial para a sobrevivência de um empreendimento gastronômico turístico.

O Modelo de Expectativa-Desconfirmação (MED) serviu como inspiração para a justificativa do tema escolhido por esse estudo. Apesar de suas limitações, inerente de qualquer modelo científico, o MED tem sido considerado como o modelo dominante para avaliação da satisfação do cliente com os serviços de hotelaria e turismo (Johns \& Pine, 2002). Resumidamente, o MED preconiza que a resposta humana de satisfação não é possível sem comparação e "conclui que as expectativas desempenham um papel chave na resposta de satisfação porque as expectativas ditam um padrão para avaliar o desempenho do produto, no futuro" (Oliver, 1996 apud Ameer, p. 77, 2014). No contexto da experiência gastronômica turística, 
um relacionamento entre cliente e empreendedor que resulte na sensação de preenchimento das expectativas do cliente pode ser considerado como satisfatória. Por outro lado, se a diferença entre expectativa e realização dos serviços for percebida como negativa, onde "necessidades, desejos e ambições não foram atendidos, a experiência terá um resultado de qualidade baixa ou insatisfatória. Fundamentalmente, no mundo da restauração, é de grande importância o entendimento entre as partes envolvidas no processo e o equilíbrio entre a qualidade na produção dos alimentos e das bebidas com a do serviço que será realizado posteriormente aos mesmos. Deve ficar claro o que está sendo oferecido e como será oferecido. De nada adianta uma produção de alto nível, com o correto uso de técnicas culinárias e ingredientes de primeira qualidade se, posteriormente, o serviço que irá disponibilizar esta produção ao cliente é feito de forma desatenciosa, de maneira inadequada ou de forma a não suprir as expectativas dos clientes.

A qualidade dos serviços na restauração, apesar de possuir um forte, e talvez, preponderante caráter subjetivo (Krause, 2014), não se restringe apenas no resultado da relação interpessoal, hospitaleira e cordial entre cliente e restaurador e tão pouco somente na preparação dos alimentos. Há, também, um componente essencial à prestação de serviços gastronômicos: as técnicas e os métodos clássicos de apresentação e de entrega do alimento ao consumidor, denominadas aqui de tipos ou estilos de serviços. Apesar do afloramento de artigos científicos nas mais diversas áreas, alguns tópicos considerados como base para o acontecimento da gastronomia permanecem ainda sem estudos aprofundados. Isso resulta uma falta de coesão entre alguns termos, conceitos e procedimentos usados, coesão essa inerente de uma área científica imatura.

Alguns conceitos e técnicas clássicas utilizadas na prestação de serviços dentro da gastronomia, como o mise en place (os tipos e a metrificação dos utensílios à mesa), a tipologia e a execução do serviço, sempre foram a base para análise de qualidade dos serviços em um estabelecimento gastronômico. Nesse sentido, a tipologia de serviços clássica, entendida aqui como a apresentação, disposição e entrega ao cliente de um prato, ou grupo de pratos que compõem a refeição ou parte dela (Lang, 1995), entre eles o serviço denominado de à francesa, por exemplo, apesar de ser utilizada há séculos, é uma dessas áreas onde muitas vezes as nomenclaturas e procedimentos são vagos, carecem de estudos aprofundados e possuem disparidade entre si, causando incoerência na prestação dos serviços. O que se percebe no cotidiano dos prestadores desse tipo de serviço é a oferta de algo diferente do que se espera, portanto, uma comunicação cheia de lacunas entre cliente e restaurador e, consequentemente, um desconforto na relação entre essas partes, impactando diretamente, de forma negativa, na percepção da qualidade dos referidos serviços. Por exemplo, "a maioria dos americanos interpretam o serviço à francesa como um serviço muito sofisticado envolvendo preparações ao lado da mesa assim como um diverso número de diferentes talheres, serviço esse que é na verdade uma combinação dos estilos à francesa, à inglesa e à russa" (Martinage \& 
Martinage, p. 120, 2013). Além da divergência entre aspectos essenciais de cada serviço, como o lado correto de servir um prato, por exemplo, há também diferentes nomenclaturas para um mesmo tipo de serviço. Cândido (2010) nomeia o serviço à russa de à inglesa indireto, o que dificulta ainda mais o entendimento sobre o assunto, causando um nível de insatisfação por parte do cliente, o qual não sabe o que esperar de cada tipo de serviço.

Apesar de sua importância socioeconômica da gastronomia para o turismo, verificouse que não há nenhum artigo cientifico sobre o assunto, de acordo com os parâmetros estabelecidos por esse estudo, que esclareça a tipologia clássica de serviços e a base lógica em que se desenvolve sua operacionalização. O referencial teórico sobre a tipologia de serviços é proveniente exclusivamente de alguns poucos livros, mostrando assim a carência de estudos científicos para essa área essencial à qualidade na prestação de serviços gastronômicos turísticos. Portanto, para que se possa almejar altos níveis de qualidade e satisfação na prestação de serviços gastronômicos turísticos é necessário, a priori, esclarecer e informar alguns conceitos básicos que ocorram, anteriormente à síntese de ideias e produção de conhecimento, uma revisão do tema a ser estudado, com a finalidade de compreender a essência do mesmo (Bressan, 2008; Marconi \& Lakatos, 2011; Martins, 2009).

A técnica de pesquisa denominada de "estado da arte" foi usada para levantar os estudos, identificar as discrepâncias e lacunas da pesquisa científica sobre o tema em questão. Apesar de não se tratar de um artigo em formato de estado da arte, esse tipo de abordagem foi usada apenas para delimitar o referencial teórico, pois os estudo de revisão são essenciais para o desenvolvimento das ciências sociais aplicadas, como o turismo gastronômico, e de extrema para os de caráter exploratório, como é o caso do tema desse artigo. Esse tipo de abordagem permite "mapeamentos, análises críticas, buscando colocar em evidência os temas e assuntos focalizados, as abordagens metodológicas, procedimentos e análises, [...] bem como as lacunas que podem estimular a produção de novas pesquisas" (Vosgerau \& Romanowski, 2014, p. 167). Ademais, facilita definições de determinadas áreas de pesquisa, auxiliando na compreensão de assuntos sem consolidação científica, "apontando as necessidades de melhoria do estatuto teórico metodológico, e mesmo as tendências de investigação. [Esses estudos podem apontar] aportes teórico-metodológicos e sua compreensão em diferentes contextos, indicar procedimentos metodológicos utilizadas na área, apontar tendências das abordagens das práticas educativas" (Vosgerau \& Romanowski, 2014, p. 168).

Portanto, o objetivo principal é o de sintetizar os conhecimentos científicos do referencial teórico com os conhecimentos empíricos dos autores desse presente artigo sobre os quatro principais tipos/estilos de serviços individuais em estabelecimentos gastronômicos de serviço completo. Esses serviços são à francesa, à russa, à inglesa e à americana (Payne-Palacio \& Theis, 2012; Kotschevar \& Luciani, 2007; Dahmer \& Kahl, 2009; Martinage \& Martinage, 2013; Lang, 1995; CIA, 2013). Como objetivos secundários, busca-se, simplificar e propor uma 
padronização dos tipos de serviços clássicos em restauração. Finda-se o estudo com a proposta de padronização e simplificação dos tipos de serviços clássicos em restauração, visando suprir a lacuna de comunicação entre cliente e empreendedor gastronômico, causada pela disparidade entre os conceitos tema do estudo. Essa padronização dá resultado à três tipos básicos de serviços completos, serviço à francesa, serviço à inglesa direto e serviço empratado (sendo os demais, como o serviço à russa, por exemplo, uma variação desses), dispostos em um quadro resumo ao final dos resultados. Como decorrência desse estudo espera-se que o mesmo fomente a pesquisa em gastronomia, visando a qualidade da mesma como parte indissociável do turismo.

\section{METODOLOGIA}

Esse estudo possui uma abordagem metodológica positivista, a qual contempla, entre outros aspectos, que os dados verificados (fatos positivos) percebidos pelos sentidos são conhecidos como evidência empírica; portanto, o positivismo é baseado no empirismo, visando também a produção de resultados práticos (Macionis \& Gerber, 2011). Por tratar-se de um tema essencial para a qualidade nos serviços gastronômicos, ainda inexplorado cientificamente, esse estudo propõem a união de duas realidades, a científica (proveniente do referencial teórico) e a empírica (provinda da experiência acadêmica e profissional dos autores). Procurando iluminar algumas relações até então desconsideradas pela literatura especializada.

Utilizou-se a técnica de pesquisa comparativa, que estuda as semelhanças e diferenças entre grupos, povos, países e/ou eventos, para entender um determinado fenômeno e/ou ampliar o nível de conhecimento sobre um evento especifico (Marconi \& Lakatos, 2003; Martins, 2009), pois é "lançando mão de um tipo de raciocínio comparativo que podemos descobrir regularidades, perceber deslocamentos e transformações, construir modelos e tipologias, identificando continuidades e descontinuidades, semelhanças e diferenças, e explicitando as determinações mais gerais que regem os fenômenos sociais" (Schneider \& Schmitt, 1998, p. 01).

A técnica de levantamento do estado da arte sobre o tema tipologia de serviços gastronômicos foi usada para compor o referencial teórico. O levantamento foi realizado entre agosto de 2015 e maio de 2016. Para artigos científicos, foram utilizadas as bases de dados disponibilizadas pela instituição de ensino dos autores, sendo essas a EBSCOhost, ScienceDirect, SciELO, Portal de Periódicos CAPES/MEC e Google Scholar (Google Acadêmico). Para o levantamento de teses e dissertações foi realizada uma varredura na Biblioteca Digital Brasileira de Teses e Dissertações (BDTD).

O recorte temporal ficou determinado em 78 anos (entre 1938 e 2016). O ano inicial de 1938 foi adotado como ponto inicial pois é o ano de lançamento da primeira edição do 
Larousse Gastronomique, considerado o marco inicial da literatura científica gastronômica (Booklist Online, 2010). Normalmente, um recorte considerado atual restringe-se a cerca de 15 anos (Gonçalves, 2008). Porém, optou-se por estender esse recorte pois, os resultados iniciais em um recorte temporal de cinco anos foram considerados insignificantes. As palavras-chave usadas foram (em português e inglês): tipos OR estilos de serviços AND gastronomia AND restaurantes - types OR styles of service AND gastronomy AND restaurants.

Após as triagens quantitativas e qualitativas, o levantamento do estado da arte resultou em uma bibliografia que pode ser categorizada em duas partes, a clássica e a contemporânea. Nesse estudo, para fins comparativos e de síntese, irá se considerar a bibliografia denominada de clássica como aquela que foi publicada de 1938 até 2001. A partir dessa data (de 2002 até 2016) considera-se como um recorte científico temporal padrão de 15 anos, denominado aqui de contemporâneo. A bibliografia clássica é composta de seis (06) obras, sendo elas em ordem cronológica de lançamento: a enciclopédia LAROUSSE GASTRONOMIQUE (Librairie Larousse, 1a ed. 1938), o livro didático FOODSERVICE MANAGEMENT (PaynePalacio \& Theis, 1a ed. 1938), o guia PRESENTING SERVICE (Kotschevar \& Luciani, 1a ed. 1996), o manual ASSOCIATE HANDBOOK (Federation of Dining Room Professionals, - FDRP, ed. Martinage \& Martinage, 1a ed. 1996), o livro REMARKABLE SERVICE (Culinary Institute of America - CIA, 1a ed. 2001) e o guia RESTAURANT SERVICE BASICS (Dahmer \& Kahl, 1a ed. 2001).

Na bibliográfica denominada de contemporânea, a grande maioria dos artigos científicos discutem a satisfação do cliente e a qualidade na prestação de serviços em suas mais diversas escalas. Os resultados mostram diversos modelos que procuram mensurar o nível de satisfação do cliente e como mensurar, também, o construto da qualidade nos serviços. Porém, não há nenhum resultado dentre os artigos científicos que contemple o tema proposto por esse estudo. Os demais trabalhos são livros, documentos on-line, apresentações de slides de aulas acadêmicas, informativos empresariais, ente outros. Os principais são, em ordem cronológica de lançamento: O manual THE WAITER \& WAITRESS AND WAIT STAFF TRAINING HANDBOOK (Arduser \& Brown, 1a ed. 2005); o site HOSPITALITY-SCHOOL.COM (2014); o guia SERVIÇOS DE ALIMENTAÇÃO E BEBIDAS (Eleutério, 1a ed. 2014); e o livro RESTAURANTE ADMINISTRAÇÃO E OPERACIONALIZAÇÃO (Cândido, 1a ed. 2010).

O conhecimento cientifico compõe o referencial teórico do presente estudo. Os conhecimentos empíricos provêm de um material compilado no decorrer dos 22 anos de experiência acadêmica e profissional dos autores. A síntese desses conhecimentos foi apresentada a um painel de validação, formado por seis profissionais da área da gastronomia. Por tratar-se de um estudo exploratório e, principalmente, qualitativo, o número de avaliadores do referido painel pode ser considerado como satisfatório, pois não há na bibliografia especializada (Bressan, 2008; Marconi \& Lakatos, 2011; Martins, 2009) um número ideal de avaliadores para compor tal painel. Tais autores pregam que, em certos casos, apenas um avaliador é valido, caso seja representativo da comunidade em questão. Considera-se que, apesar 
de tratar-se de um número relativamente baixo, o painel é representativo, pois é composto por pessoas que possuem vasta experiência profissional sobre o tema do estudo, em restaurante nacionais e internacionais, alguns deles estrelados pelo Guia Michelin.

Ao final da exposição dos resultados criou-se uma tabela contendo uma síntese dos tipos de serviços gastronômicos, obtidos através da literatura especializada, adicionados de considerações e aspectos empíricos de ordem pessoal e profissional dos autores, obtidos através da lógica operacional, no decorrer da atuação mercadológica e acadêmica de ambos. Essa metodologia é ousada, pois propõem a união do lado empírico e do cientifico, afim de ampliar o conhecimento existente. Em um segundo estudo, uma pesquisa de campo há de ser aplicada a fim de demonstrar como os conceitos teóricos estão sendo abordados pelo mercado gastronômico brasileiro.

\section{REFERENCIAL TEÓRICO}

Os serviços em gastronomia devem priorizar o conforto e conveniência do cliente, devendo ser eficiente e estar em sintonia com o esperado pelo consumidor final. Historicamente os tipos de serviços de nominados de à francesa, à inglesa e à russa "eram nomes correspondentes à estilos de serviço completo e individual" (Martinage \& Martinage, p. 120, 2013). Com o passar do tempo, e com a estabilização e unificação da Europa, esses estilos foram se combinando. Quando migraram para o continente americano, essas combinações ocorreram de forma ainda mais elevada, dando origem ao serviço à americana (Martinage \& Martinage, 2013). Faz-se necessário o esclarecimento dos principais aspectos relacionados aos quatro principais serviços completos individuais da gastronomia e suas variações, assim como as discrepâncias entre as diferentes teorias e, portanto, onde o referencial teórico peca em padronizar a execução dos serviços.

\subsection{Serviço à Francesa ou Serviço à Diplomata}

O recorte temporal escolhido por esse estudo, estabelece o ponto inicial de observação como o reinado de Luiz XIV, onde o serviço à Francesa atingiu seu ápice. O Serviço à Francesa é uma continuação de uma cerimônia realizada pela família real francesa do século XVII, intitulada como o grand couvert, na qual a realeza o utilizava, inicialmente, somente em ocasiões especiais e para seus jantares em público, devido aos seus altos custos (Lang, 1995). Posteriormente Luiz XVI realizou o grand couvert diariamente em todas os seus jantares, pontualmente as 22:00 (Chateau de Versailles, 2016), padronizando alguns dos aspectos do serviço, hoje, intitulado à francesa.

Esse tipo de serviço, dentro dos padrões estabelecidos historicamente, não é mais utilizado. Ele teve o auge de sua ampliação e refinamento por volta de 1690 e seus últimos anos 
se deram por volta de 1830, onde fora substituído pelo serviço à russa (Lang, 1995). Tradicionalmente, uma refeição servida à francesa era dividida em três partes: "o primeiro serviço cobria o menu desde as sopas até os assados, incluindo os hors d'ouvre e entradas; o segundo, dos assados[...] e vegetais, até os pratos doces; e o terceiro, consistia das pastelarias, petit four, doces, gelados e frutas. A ordem do menu dependia do número de entradas; o número de pratos servidos no primeiro serviço tinha que ser igual àqueles do segundo serviço. Os pratos do primeiro serviço eram dispostos à mesa (em pratos quentes ou sob cobertura, caso necessário) antes da chegada dos convidados", enquanto os demais pratos eram colocados no lugar dos anteriores, e cada convidado se servia a seu gosto, assim que os pratos eram dispostos na mesa, sendo os pratos trocados rapidamente, a cada 15 minutos (Lang, p. 967, 1995). Quando uma parte do serviço era finalizada pelos comensais, "esses se levantavam e deixavam a mesa, enquanto essa era limpa preparada para o próximo serviço" (CIA, p. 39, 2013).

Além dos aos altos custos para se realizar uma refeição dentro desses parâmetros, esse tipo de serviço caiu em desuso devido ao seu alto nível de ostentação e extravagância em detrimento ao conforto e satisfação dos convidados (Payne-Palacio \& Theis, 2009). Pois, esses últimos não conseguiam satisfazer seus apetites e muito menos apreciar os pratos principais ainda quentes, haja vista que as opções eram vastas e o tempo para o aproveitamento cada prato era curto, para que pudessem ser servidos o maior número de pratos em uma única refeição (LANG, 1995). Esse serviço foi ampliando, modificando e adaptando-se com o passar do tempo em diversos locais, dando a ele algumas características contemporâneas reconhecidas nos dias de hoje, como por exemplo, e principalmente, a finalização ou serviço de algumas preparações ao lado da mesa com o guéridon ou "carrinho de flambar". No entanto, vale relembrar que o serviço à francesa tradicional ainda permanece vivo, ainda que em poucas ocasiões, nas embaixadas francesas ao redor do mundo e no Palácio Presidencial da França (Martinage \& Martinage, 2013).

Esse tipo de serviço, tem como principal característica dois aspectos: o uso do guéridon e, por consequência, a finalização ou até mesmo a preparação de alguns itens ao lado cliente, atos esses realizados pelo "chef de rang (chefe de praça), que é assistido por um commis ou talvez commis debarasseur (debarass significa para limpar ou tirar); e, em um segundo momento, a apresentação da comida ao cliente onde esse mesmo se serve, pela esquerda (Cândido, 2010; Eleutério, 2014; Dahmer \& Kahl, 2001; Martinage \& Martinage, 2013). No entanto, alguns autores (Payne-Palacio \& Theis, 2009; CIA, 2013; Arduser \& Brown; 2005) nem sequer mencionam por qual lado o serviço deve ser realizado, causando assim uma possível falta de padronização desse tipo de serviço.

Além de preparar a comida, o chef de rang a emprata e coloca as guarnições. Pratos aquecidos são utilizados para comida quente. O prato preparado é, em seguida, entregue aos commis, que o apresenta para o convidado" (Kotschevar \& Luciani, p. 111, 2007). O bom 
senso estabelece quais pratos são preparados previamente, pois "apenas os alimentos que podem ser cozinhados, montados ou concluídos em um tempo razoavelmente curto são preparados na frente dos convidados. Especialidades típicas que podem ser servidas no estilo francês são La Salade C'esar (salada Caesar), Le Tournedos au Poivre (filé ao molho de pimenta), e Les Crepes Suzette (crepes em molho de laranja)" (Dahmer \& Kahl, p. 19, 2001).

Essa peça auxiliar é, tradicionalmente, uma pequena mesa redonda, e adaptada ao serviço de mesa. Geralmente, "ela é equipada com um réchaud (elemento aquecedor) e um grande domo de prata ou cloche para cobrir a comida" (CIA, p. 40, 2013). O guéridon deve conter todos as ferramentas necessárias para a preparação, finalização e o serviço dos alimentos ao cliente, podendo ser usado para preparar e servir desde saladas, desossar peixes ou trinchar carnes. A variação mais comum desse tipo de serviço é a utilização de travessas ao invés do guéridon. Nesse caso, "a comida é preparada totalmente ou parcialmente na cozinha, colocada em travessas e carregada até o salão de jantar pelo garçom. A travessa é então colocada em cima do guéridon ou mesa aquecedora e empratada" o garçom apresenta a travessa ao cliente e esse mesmo se serve (CIA, p. 40, 2013).

As tarefas e técnicas mais comumente vistas a serem desempenhadas pelo chefe de praça são: Toss and Mixing (saltear e misturar); Plate Presentation and Sauces (empratamento e molhos); Deboning and Carving (desossar e trinchar); e Flambéing (flambar) (Kotschevar \& Luciani, p. 113, 2007). Contemporaneamente, o uso do guéridon tem sido limitado a um serviço à francesa tido como exclusivamente formal e tradicional (CIA, 2013), pois requer mais tempo de serviço e habilidade da brigada de trabalho, sendo assim fica comercialmente viável trazer os alimentos prontos da cozinha à mesa (Cândido, 2010).

\subsection{Serviço à Russa ou Serviço à Inglesa Indireto}

Foi o príncipe e embaixador (entre os anos de 1810 e 1812) da Rússia na França, Alexander Borisovich Kurakin, durante o segundo império russo, quem introduziu as primeiras modificações ao serviço francês até chegar ao ponto desse novo serviço ser denominado de à Russa, pela alta sociedade francesa (Lang, 1995). A partir de então, ele se espalhou pelo mundo, principalmente devido à sua popularização através do chef francês e criador de diversos clássicos da culinária francesa. Urbain Dubois, o qual introduziu o serviço à Russa nos lares da classe média francesa (Lang, 1995). Ele definiu o novo estilo de serviço como menos formal e menos ostentador. Seu objetivo era fazer com que os convidados, ao oposto do serviço à francesa, pudessem degustar "os pratos quentes os mais quentes possíveis; ao invés de deixar o convidado escolher dentre uma vasta gama de pratos, a ordem era estabelecida previamente e os pratos apresentados um após o outro" (Lang, p. 968, 1995). Luxo e extrava- 
gância foram substituídos por conveniência e praticidade, tendo em vista o conforto e comodidade. No entanto, a apresentação e aparência da comida continuaram a ter grande importância.

O serviço à Russa é semelhante ao serviço francês em muitos aspectos, sendo grandemente modificado no decorrer dos anos até se tornar um estilo de serviço distinto. É um tipo de serviço muito formal e elegante, e é dado considerável atenção pessoal ao convidado. É considerado o estilo de serviço mais popular e é usado na maioria dos melhores restaurantes e hotéis do mundo. Devido à sua relativa simplicidade em comparação ao serviço francês, o substituiu a um grau elevado. Ainda assim, ele emprega o uso e o ajuste de mesa praticamente idênticos à configuração do serviço francês (Lang, 1995; CIA, 2013; Payne-Palacio \& Theis, 2009; Martinage \& Martinage, 2013; Dahmer \& Kahl, 2001; Kotschevar \& Luciani, 2007).

As duas principais diferenças são que apenas uma pessoa é necessária para realizar o serviço e que a comida é totalmente preparada na cozinha. A comida, então, é disposta em bandejas de prata, levada ao salão pela brigada de trabalho e é transposta no prato do convidado pelo próprio servidor (anfitrião, maître, garçom, etc.). As preparações já estão finalizadas quando saem da cozinha, sendo o uso do guéridon opcional e somente para finalizações e aquecimento dos pratos (Martinage \& Martinage, 2013). É um tipo de serviço menos trabaIhoso, requer um nível de experiência e conhecimento menos elevados do que o serviço francês, sendo assim, também é mais rápido e menos custoso. Também requer menos espaço, é bem adaptado para o serviço de grandes grupos que irão desfrutar de mesma refeição, e ainda pode ser muito elegante. Ainda assim, os comensais, como no serviço francês, sentem que eles estão recebendo um serviço personalizado, devido à maneira como são servidos (Lang, 1995; ClA, 2013; Payne-Palacio \& Theis, 2009; Martinage \& Martinage, 2013; Dahmer \& Kahl, 2001; Kotschevar \& Luciani, 2007).

Este serviço é baseado em um princípio básico: tudo deve ser executado em um mínimo de tempo, de modo que o prato é apresentado rapidamente, sem alterar o seu sabor. Es convidados são divididos em grupos de 8, 10 ou 12 pessoas, onde cada um desses grupos é atendido por um maître d'hôtel (palavra francesa que significa "mestre", conhecido popularmente no Brasil simplesmente como maître). Antes de dar início ao serviço, já é estabelecido qual convidado de cada grupo será servido primeiro, e os demais são servidos em sentido horário a partir do primeiro (Lang, 1995).

Para servir, o maître traz os pratos de comida da cozinha para a sala de jantar e apresentá-los para os convidados à mesa. Logo após, coloca-se a travessa "ante de cada hóspede, do lado esquerdo. Em seguida, de pé à esquerda de cada convidado e segurando o prato de comida na mão esquerda, o maître mostra a cada convidado a comida e usando uma grande colher e um garfo na mão direita, porciona a parte desejada no prato do convidado" (Dahmer \& Kahl, p. 21, 2001). Alguns autores (CIA, 2013; Arduser \& Brown, 2005), confundem e/ou 
não mencionam por qual lado deve-se fazer o serviço, causando confusão entre os tipos de execução.

Seguindo a linha tida como correta, as "porções de alimentos são levantadas a partir da travessa de serviço pela mão direita do maître, colocando uma colher grande com a taça para cima debaixo de uma porção e um garfo é colocado em cima para mantê-la no lugar. Uma colher é usada para servir legumes e muitos outros itens" (Kotschevar \& Luciani, p. 116, 2007). O serviço continua em sentido horário ao redor da mesa e, em seguida, retorna a comida restante para a cozinha, e o vinho é servido na mesma ordem, como os pratos, porém a primeira dose é servida ao anfitrião (Lang, 1995). O uso do guéridon no serviço à russa também é comum desde que a comida já venha preparada da cozinha, não sendo finalizada à mesa, sendo somente transposta ao prato do convidado (CIA, 2013).

\subsection{Serviço à Inglesa (tradicional)}

O serviço à inglesa, também conhecido como "serviço de anfitrião" (Arduser \& Brown, 2005), provem dos tradicionais lares da aristocracia britânica, onde "o chefe da casa agia como o 'trinchador' e servia as porções à família e convidados com a assistência de empregados domésticos" (Martinage \& Martinage, p. 123, 2013). Posteriormente, esse tipo de serviço foi comercialmente estendido aos clubes de campo do Reino Unido (CIA, 2013). O serviço à inglesa, é menos formal, menos trabalhoso e, consequentemente, menos custoso, e consideravelmente mais rápido. É um estilo de serviço mais íntimo e pessoal, com relações mais próximas às demonstrações de hospitalidade genuína, remetendo às imagens familiares e aos lares britânicos. Por essa razão, tem uma graciosidade desejável com grupos mais íntimos, podendo ser usado ocasionalmente para um jantar especial servido em uma sala de jantar privada de um restaurante (CIA, 2013; Martinage \& Martinage, 2013). Assim como o serviço à russa, toda a comida é preparada na cozinha e trazida ao salão de jantar somente para ser disposta e servida aos convidados/clientes (CIA, 2013; Martinage \& Martinage, 2013; Dahmer \& Kahl, 2001; Kotschevar \& Luciani, 2007).

O anfitrião, em ocasiões particulares representado pelo chefe da casa, serve a comida proveniente de travessas, tigelas e/ou vasilhas que são trazidas da cozinha e dispostas na ponta da mesa onde ele está sentado (CIA, 2013; Martinage \& Martinage, 2013; Dahmer \& Kahl, 2001; Kotschevar \& Luciani, 2007). Tradicionalmente, ele trincha, desossa, fileta ou porciona qualquer que seja o prato principal, colocando-os nos pratos individuais juntamente com as guarnições e assim que o prato está completo o próprio anfitrião serve cada indivíduo, colocando o prato à frente do convidado. Alternativamente, o anfitrião apenas trincha o prato principal e coloca a porção no prato, passando, em seguida, o prato à pessoa a sua esquerda (geralmente a segunda pessoa na hierarquia da casa), e essa serve as guarnições e entrega o 
prato ao convidado de honra e aos demais convidados, sendo que o próprio anfitrião estabelece a ordem devido a importância dos convidados ou da ocasião (Martinage \& Martinage, 2013; Dahmer \& Kahl, 2001; Kotschevar \& Luciani, 2007). Em outra opção de serviço, menos formal e mais contemporânea, o anfitrião passa o prato para a pessoa mais próxima de sua posição, e essa pessoa passa o prato para o convidado ao lado, e assim sucessivamente, até que os pratos cheguem a todos os convidados (CIA, 2013).

\subsection{Serviço à inglesa direto}

O serviço à inglesa (tradicional) não é viável comercialmente. Porém, esse tipo ser serviço dada as corretas adaptações e variações é útil, comercialmente, em eventos ou em restaurantes reservados para grupos privados, onde, após a comida ser trazida da cozinha, uma parte da brigada de serviço serve os pratos e os demais servidores levam, apresentam e distribuem os respectivos pratos aos convidados. Em restaurantes, as técnicas do serviço à inglesa são adaptadas à uma execução mais formal, possuindo algumas variações (Martinage \& Martinage, 2013) para que seja executado em um restaurante em um dia de operação normal e não somente em eventos ou jantares privados. Nesse caso, essa variação é denominada de à inglesa direto, e caracteriza-se, principalmente por dois aspectos. Primeiramente, a comida já vem totalmente preparada e montada em recipientes adequados da cozinha, não requerendo nenhuma finalização no salão de jantar, à frente do cliente. Em segundo lugar, o garçom apresenta o recipiente com o alimento do lado esquerdo do cliente, e usando os talheres de serviço (colher em baixo e garfo em cima, ambos virados para cima, em forma de pinça) serve uma porção do alimento diretamente no prato do cliente (Martinage \& Martinage, 2013). Porém, alguns autores preconizam que a comida deve ser servida pelo lado direito " (Arduser \& Brown, 2005), causando discrepância nos conceitos e desentendimento entre cliente e servidor.

\subsection{Serviço à Americana ou Serviço Empratado}

O serviço à Americana (visto como uma junção dos três serviços vistos anteriormente) é considerado o estilo menos formal, menos custoso e mais eficiente dentre os vistos anteriormente, retendo ainda um certo nível de elegância (CIA, 2013). Talvez seja hoje o tipo de serviço mais popular no mundo da restauração e, portanto, possui diversas nomenclaturas e variações, sendo chamado de o serviço simples, empratado ou serviço ao prato, executivo e, ainda, A l'assiete (Cândido, 2010; Lang, 1995; Dahmer \& Kahl, 2001; Martinage \& Martinage, 2013; CIA, 2013; Kotschevar \& Luciani, 2007). Porém, todos compartilham uma característica básica. Essencialmente, todas as preparações são porcionadas e montadas em pratos indivi- 
duais na cozinha, somente então são levadas e apresentadas aos comensais (CIA, 2013; Dahmer \& Kahl, 2001; Kotschevar \& Luciani, 2007; Lang, 1995; Martinage \& Martinage, 2013). Devido ao fato dos alimentos serem preparados, montados e decorados na cozinha pelo chef ou "sob a supervisão de chefs profissionais, a comida quando chega ao convidado pode ser muito atraente [...] Muitos chefs acolhem o serviço americano, porque lhes dá a oportunidade de mostrar a sua criatividade, organizando itens alimentares individuais de uma forma que é visualmente atraente" (Kotschevar \& Luciani, p. 116, 2007).

Esse tipo de serviço foi adaptado às necessidades dos Estados Unidos em otimizar custos, ser eficiente, permitindo uma alta taxa de rotatividade de mesas servidas e alto volume de vendas (CIA, 2013). Outras vantagens do serviço à americana é que esse pode ser facilmente modificado para atender às diversas situações e necessidades, assim, podendo ser variado para se adequar ao serviço do café da manhã, almoço ou jantar (Kotschevar \& Luciani, 2007).

Apesar de alguns autores (Payne-Palacio \& Theis, 2009) não determinarem a ordem do serviço, a regra geral é que o servidor se aproxime do comensal pela direta, com o prato preparado na cozinha, sobre seu braço esquerdo, colocando o prato com a mão direita na frente do comensal (CIA, 2013; Dahmer \& Kahl, 2001). Adicionalmente, fomentando ainda mais o desentendimento, Kotschevar \& Luciani (2007) apresentam o serviço pela esquerda do cliente, sem justificá-lo. Martinage \& Martinage (2013) preconizam que a execução desse estilo de serviço deve priorizar, diferente dos demais, a mão predominante do servidor, no intuito de facilitar e agilizar o serviço. Os autores supracitados, declaram que a "violação" dessa regra é permitida, e até bem-vinda, caso o com o servidor seja canhoto. Isso permite que o servidor carregue dois ou até três pratos com o braço de uso menos habitual e sirva-os com a mão predominante, garantido a colocação do prato na frente do comensal com mais agilidade, segurança e precisão (Martinage \& Martinage, 2013).

\section{RESULTADOS}

Haja vista que o serviço à inglesa tradicional não é viável comercialmente e o presente estudo foca na restauração comercial, esse serviço fica relegado a ocasiões familiares e privadas e, portanto, não é contemplado nos resultados finais, assim como o serviço à russa. Portanto, comercialmente estabelece-se os quatro serviços clássicos como à francesa, à inglesa direto (sendo o indireto apenas uma variação desse, utilizando-se o guéridon) e o serviço empratado. Essa pesquisa propõe criar uma tentativa de um diálogo entre dois sujeitos distintos: um, da perspectiva do referencial teórico, e outro da ótica empírica dos autores (profissional e acadêmica) do presente estudo, buscando sintetizar, simplificar e padronizar as definições sobre a tipologia de serviços em restauração (quadro 02). Essa síntese foi tes- 
tada parcialmente por um pequeno painel de avaliadores, visando validar, validar parcialmente ou refutar os resultados propostos. Esse painel é composto por seis avaliadores, três chefs e três hostesses ("anfitriãs", em tradução literal - nome dado às pessoas que recebem o cliente e ajudam no fluxo do serviço), todos eles possuem experiência nacional e internacional em restaurantes de serviço completo, alguns desses estrelados pelo guia Michelin.

Essa proposta, tem como premissa básica que todas as regras para realização do serviço têm em vista a prioridade para pessoas destras e visam sempre a facilitação do uso dos utensílios e da operação dos serviços. Nunca se deve cruzar a frente do cliente na execução do serviço, devendo assim determinar-se quais os lados pelos quais se farão os serviços de pratos e bebidas ao cliente, bem como a retirada de pratos e utensílios da mesa. Os resultados do painel de validação encontram-se no quadro 01.

Quadro 01 - Resultados do painel de validação

\begin{tabular}{|l|c|c|c|}
\hline & Serviço à francesa & Serviço à inglesa direto & Serviço empratado \\
\hline Avaliador 01 & Válido integralmente & Válido integralmente & Válido integralmente \\
\hline Avaliador 02 & Válido parcialmente & Válido integralmente & Válido integralmente \\
\hline Avaliador 03 & Válido parcialmente & Válido integralmente & Válido integralmente \\
\hline Avaliador 04 & Inválido & Válido integralmente & Válido integralmente \\
\hline Avaliador 05 & Inválido & Válido integralmente & Válido integralmente \\
\hline Avaliador 06 & Inválido & Válido integralmente & Válido integralmente \\
\hline
\end{tabular}

Fonte: autores (2016)

A única discordância entre o proposto pelo estudo e a avaliação do painel de validação diz respeito ao serviço à francesa. No entanto, o painel não discorda da metodologia proposta para padronizar e simplificar o serviço, apenas ressalva que esse tipo de serviço, especialmente com o uso do guéridon, "está em desuso, [...] é desconfortável para o cliente [e] muito confuso de executar, tanto para o comensal quanto para o garçom" (Autores, 2016). Procurou-se padronizar e simplificar, também a nomenclatura desses serviços, optando-se pela nomenclatura de serviço à francesa ao invés de serviço à diplomata, pois nesse último requer uma hierarquia e formalidade que não são utilizados comercialmente. Optou-se por inglesa indireto, em detrimento do serviço à russa, pois os termos direto e indireto facilitam o entendimento e a padronização da nomenclatura. A única diferenciação reside no fato de que no serviço (denominado também de suíte) direto os alimentos já vêm prontos da cozinha e vão direto ao prato do cliente. Enquanto que no serviço indireto, os alimentos providos da cozinha requerem alguma finalização (geralmente usando-se o guéridon) na frente do cliente antes de ir ao prato (figura 01). 
Figura 01 - Fluxo dos serviços clássicos em restauração
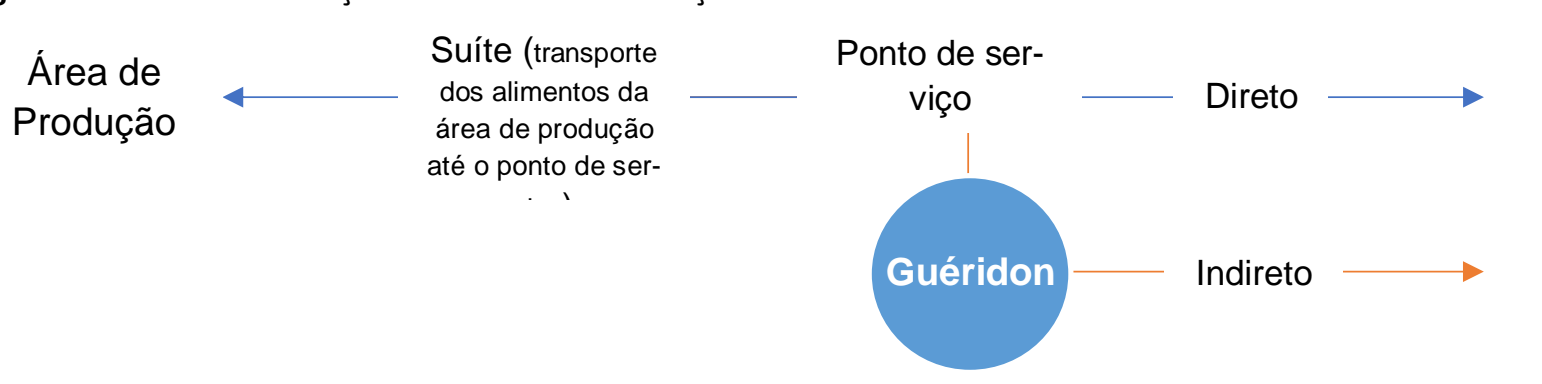

Fonte: autores (2016)

Optou-se pela nomenclatura de Serviço Empratado ao invés de à americana, propondo a padronização da nomenclatura, relacionando-a sua característica essencial (a comida vinda da cozinha já porcionada no prato do cliente). Propõem-se, desvincular a nomenclatura do serviço do país, pois esse tipo de serviço (ao contrário do serviço à francesa e inglesa) não foi inventado nos Estados Unidos da América. Ademais, esse tipo de serviço é, também, comumente utilizado na Itália e França, em diversos tipos estabelecimentos da área gastronômica, desde restaurantes básicos que servem o chamado aqui no Brasil de "prato feito", até restaurantes da alta gastronomia como o D.O.M do chef Alex Atala, em São Paulo. Inclusive, em diversos meios nos E.U.A esse tipo de serviço é conhecido e chamado como platter service ("empratado", em uma tradução livre).

Serviço à francesa - atualmente, o serviço à francesa tradicional (com o uso do guéridon para preparo e finalização de alimentos) está relegado à salões de festas formais e a poucos e exclusivos restaurantes de alto padrão (Arduser \& Brown, 2005), pois requer um alto nível de sofisticação e preparo da brigada de serviço. Além disso, "geralmente requer um capitão para assentar os convidados e tomar nota dos pedidos, um sommelier para auxiliar na seleção e no serviço dos vinhos, um garçom de frente e de fundo para preparar e servir a comida, e um commis para trazer a água e o pão" (ClA, p. 39, 2013), assim como para desfazer, limpar e refazer a mesa. O serviço à francesa tradicional, por ser bastante formal, conta com necessidade de uma brigada experiente na sua execução e comercialmente é pouco utilizado por ser demorado e não deixar o cliente à vontade. É um serviço que, por priorizar a hierarquia na sua sequência, é bastante usado em almoços e jantares de autoridades, principalmente entre chefes de estado, daí ser conhecido também, como serviço diplomata.

Base para execução: no Brasil o serviço à francesa é realizado com os alimentos produzidos na cozinha, já porcionados e colocados em um guéridon (somente para mantê-los aquecidos) ou em uma travessa. São usados o garfo e colher para a transposição dos alimentos ao prato do comensal. Esses utensílios são dispostos na ponta da travessa, com os cabos voltados para 
fora. A travessa é conduzida pelo garçom, apoiada na mão esquerda do mesmo, sobre um guardanapo de serviço, até o cliente. Para servir o cliente o garçom aproxima-se pelo lado esquerdo do mesmo, leva a travessa até próximo ao prato do cliente sem encostar-se à mesa nem no prato. Nesta posição os talheres para o serviço, que se encontram na travessa, devem ter sido arrumados para que seus cabos fiquem voltados ao cliente. Este pegará os talheres e com eles fará a transposição dos alimentos da travessa para o seu prato (figura 02). Características complementares: o serviço à francesa é executado com um garçom para 6 a, no máximo, 8 clientes, iniciando os serviços sempre pelas autoridades hierarquicamente superiores ou convidados e terminando pelo anfitrião. No caso de não haver hierarquia por autoridade, inicia-se sempre pelas mulheres convidadas ou por idade, seguindo-se dos homens da mesma forma. É sempre interessante verificar-se o protocolo onde estarão relacionadas as classes hierárquicas. A lógica da execução: este serviço é idealizado para as pessoas destras, portanto priorizando a grande parte da população. Portanto, o serviço é feito pelo lado esquerdo do cliente porque é a forma do mesmo ter a mão direita mais longe da travessa e, portanto, mais livre para fazer os movimentos necessários à transposição dos alimentos. A mão esquerda fica comprometida e com movimentos limitados devido à proximidade com a travessa, servindo apenas para apoio à mão direita, essa livre. Caso isto fosse feito no lado direito, a maioria dos clientes teriam muitas dificuldades de executar a operação da forma prevista.

Figura 02 - Visualização esquemática do serviço à francesa

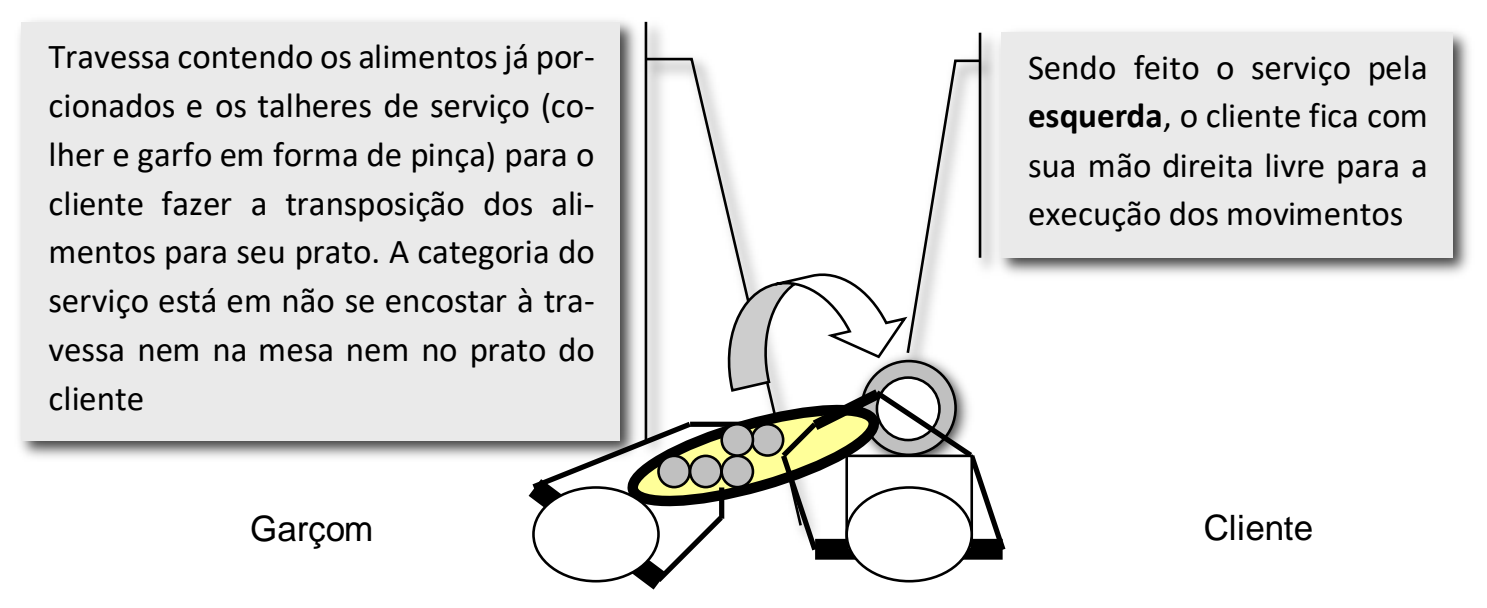

Fonte: Autores (2016)

Serviço à inglesa direto - é uma variação simplificada do serviço à francesa visto anteriormente, só que, neste caso, quem faz a transposição do alimento da travessa para o prato do cliente é o garçom. $O$ indireto caracteriza-se, simplesmente pelo uso do guéridon somente para finalização, e nada de preparo, de alguns alimentos. Base para execução: os alimentos 
são dispostos em uma travessa já porcionados, na cozinha, ou sendo porcionados pelo garçom antes de executar o serviço. Algumas vezes o porcionamento só é feito após a apresentação do prato ao cliente como forma de preservar a decoração realizada pela cozinha. Pelo lado esquerdo do cliente, o garçom aproxima a travessa, com os alimentos já porcionados, do prato do cliente. Utilizando-se dos talheres de serviço na mão direita, em forma de "pinça", o garçom realiza então a transferência do alimento para o prato do cliente (figura 03).

Características complementares: este serviço tem como parâmetro, a capacidade de um maître/garçom atender até 6 a 8 clientes com o auxílio de um ou dois commis. A travessa pode, inicialmente, ser apresentada ao cliente, pelo lado direito, para que o mesmo verifique se está de acordo com o pedido. É, também, o momento de se mostrar ao cliente a travessa decorada. Após sua aprovação é que o garçom se dirige ao lado esquerdo do cliente e dá início ao serviço. O garçom, quando transfere os alimentos da travessa para o prato do cliente, deve ter o cuidado de fazer sua disposição de forma harmônica e com um bom visual. Normalmente, a forma de fazer esta arrumação é combinada junto com o maître e o chef, considerando destacar, além do visual, as características próprias do preparo. A destreza no uso dos talheres de serviço na forma de "pinça" são um dos pontos mais importantes na qualidade deste serviço. A lógica da execução: no caso do serviço à inglesa direto, o ponto de referência para determinação do lado de execução do serviço é o garçom (pois esse é quem serve a comida), e não mais o cliente. Isto tem por base o critério que, sendo o garçom destro, ele usará os talheres de serviço na forma de "pinça" na mão direita e, que a mesma, fique entre a travessa e o prato. Esta é a maneira de se fazer a transposição com o menor esforço. Se fosse realizada pelo lado direito, um garçom destro, ficaria com a travessa entre a sua mão direita (com os talheres de serviço em "pinça") e o prato do cliente, dificultando enormemente a execução do serviço. O uso dos talheres em forma de "pinça", permite que com a variação da forma de segura-los, se faça a transposição de peças porcionadas, de guarnições (inclusive de massas de fio, como macarrão e espaguete), do molho e de outros como um guardanapo. 
Figura 03 - Forma esquemática de representar o serviço à Inglesa Direto

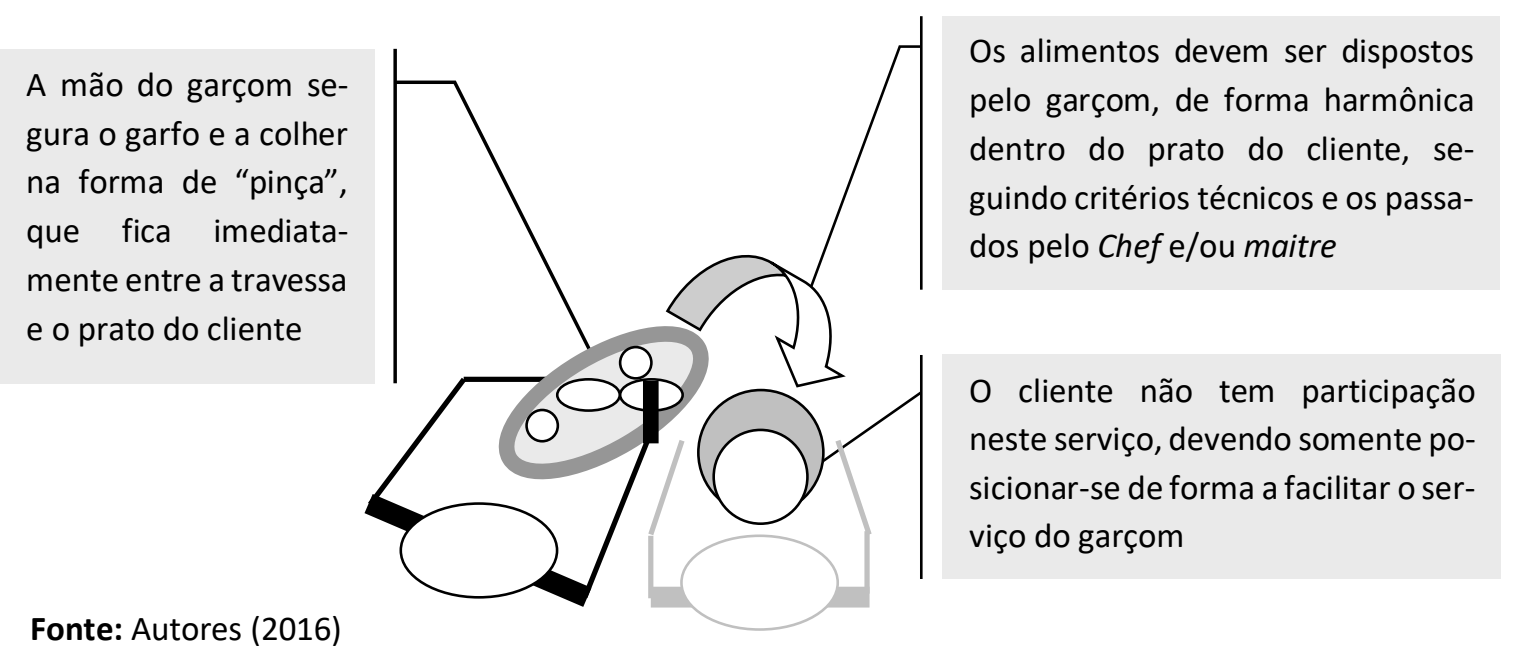

Serviço Empratado - será feita aqui, uma simplificação da nomenclatura, considerando que este serviço terá como ponto referencial, a colocação para o cliente do prato já servido. Desta maneira, poderão estar enquadrados como serviço empratado, as seguintes denominações: A l'assiette - (em tradução livre "ao prato") que é o serviço de pratos empratados na cozinha, com grande preocupação na forma estética; À italiana - equivalente ao l'assiette, porém um pouco mais simples, mas ainda retende certo nível de refinamento, na sua apresentação, usado principalmente com massas e risotos; Executivo ou Prato Feito - nome dado no Brasil ao serviço a l'assiette executado de maneira ainda mais simples, consistindo em um serviço onde é colocada, na cozinha, uma grande quantidade de alimentos em um prato, sem preocupação excessiva com a apresentação do mesmo. Base para execução: são diversas as possibilidades, como já visto anteriormente, mas o ponto de referência é que o prato, será colocado para o cliente já montado; o garçom pega o prato já servido com a mão direita e, pela direita do cliente coloca-o à sua frente (figura 04). Reafirmando, todos estes serviços têm como ponto comum, o fato dos pratos serem colocados aos clientes já servidos, variando, basicamente, na forma de sua apresentação, mais ou menos requintada e, no local onde os preparos são montados no prato. Estes locais, com base no que foi visto, podem ser a cozinha, um guéridon, uma mesa ou um aparador de apoio. 
Figura 04 - Visualização esquemática do serviço de prato individual

O cliente não participa
deste serviço, devendo
somente posicionar-se de
forma a facilitar os movi-
mentos do garçom

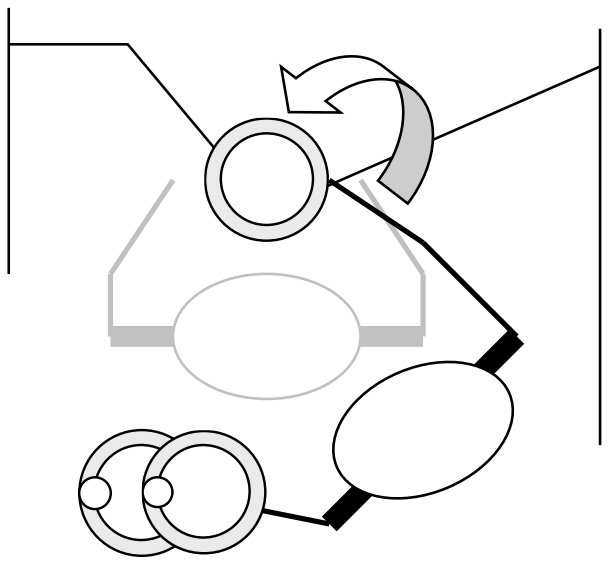

O garçom coloca o prato na frente do cliente, respeitando o centro do espaço e o logotipo, se houver, na parte superior e perpendicular à borda da mesa

Fonte: autores (2016)

Características complementares: No serviço de prato individual, caso exista prato de mesa no mise-en-place básico, este será retirado de forma simultânea pelo lado esquerdo, enquanto o prato servido é colocado pela direita (é o chamado pêndulo). É uma exceção, pois os pratos de mesa são sempre retirados pelo lado direito. A lógica da execução: para o garçom destro, a única forma possível de, com a mão direita, colocar naturalmente o prato diante do cliente, é fazendo isto pela direita do mesmo. No caso de trazer três pratos, serve inicialmente o que está trazendo na mão direita, na sequência pega, outro que está na mão esquerda, serve e repete a operação.

Variação: uma sofisticação desse tipo de serviço pode ser denominada a la cloche. No caso de o prato estar coberto com um cloche (um utensílio de cobertura de pratos), após ter sido colocado o prato para o cliente, o garçom levanta um pouco o mesmo, o desvira (devendo fazer isto ainda sobre o prato), e já com a boca para cima retira-o da mesa. Essa operação é feita para evitar que a água de condensação no cloche molhe a toalha ou o cliente. Ainda no caso do uso de cloche, recomenda-se que o garçom traga somente um, sendo que, excepcionalmente, para se adequar ao volume de atendimentos, pode-se trazer dois, um na mão direita e outro na mão esquerda. Este serviço quando utilizando cloche, pode ser feito com simultaneidade para todos os clientes de uma mesa. Para isto devem ser trazidos todos os pratos dos clientes de uma mesa até um apoio próximo à mesma e utilizado um número de garçons igual ao número de clientes (normalmente nestes casos utilizam-se commis e, se necessário, garçons de outras praças). Cada um pegará um prato com cloche, se aproximará do cliente pelo seu lado direito e, ao comando do maître, todos colocarão de forma simultânea o prato na frente dos clientes. Com outro sinal do maître, todos retirarão, também de forma simultânea, os cloches. 
Quadro 02 - Padronização simples da tipologia clássica dos serviços em restauração

\begin{tabular}{|c|c|c|c|c|}
\hline & Principais características & Direita ou esquerda & A lógica da execução & Variações \\
\hline $\begin{array}{l}\text { Serviço à } \\
\text { Francesa }\end{array}$ & $\begin{array}{l}\text { 1. A comida já vem pronta da cozinha, dis- } \\
\text { posta e porcionada em seu recipiente } \\
\text { adequado } \\
\text { 2. A transferência da comida ao prato é } \\
\text { feita pelo próprio cliente }\end{array}$ & $\begin{array}{l}\text { O recipiente com o ali- } \\
\text { mento é apresentado ao } \\
\text { cliente pelo lado es- } \\
\text { querdo }\end{array}$ & $\begin{array}{c}\text { Pela esquerda. Dessa forma, o cliente fica com os } \\
\text { movimentos da mão esquerda limitados, servindo } \\
\text { essa apenas de apoio. A mão direta direita fica livre, } \\
\text { para agir como mão dominante na transposição dos } \\
\text { alimentos ao prato }\end{array}$ & $\begin{array}{l}\text { Pode-se usar o guéridon para } \\
\text { preparação e finalização de al- } \\
\text { guns pratos (sendo denominado } \\
\text { de à francesa tradicional) }\end{array}$ \\
\hline $\begin{array}{l}\text { Serviço à in- } \\
\text { glesa direto }\end{array}$ & $\begin{array}{l}\text { 1. A comida já vem pronta da cozinha, dis- } \\
\text { posta e porcionada em seu recipiente } \\
\text { adequado } \\
\text { 2. A transferência da comida ao prato é } \\
\text { feita pelo maître/garçom }\end{array}$ & $\begin{array}{l}\text { O recipiente com o ali- } \\
\text { mento é apresentado ao } \\
\text { cliente pelo lado es- } \\
\text { querdo }\end{array}$ & $\begin{array}{l}\text { Pela esquerda. Dessa forma, o servidor fica com os } \\
\text { movimentos da mão esquerda limitados, servindo } \\
\text { essa apenas de apoio para a travessa. A mão direta } \\
\text { direita fica livre, para agir como mão dominante na } \\
\text { transposição dos alimentos ao prato }\end{array}$ & $\begin{array}{l}\text { Pode-se usar o guéridon para fi- } \\
\text { nalização e aquecimento de al- } \\
\text { guns pratos (sendo denominado } \\
\text { de à inglesa indireto) }\end{array}$ \\
\hline $\begin{array}{c}\text { Serviço Em- } \\
\text { pratado }\end{array}$ & $\begin{array}{l}\text { 1. A comida já vem da cozinha disposta no } \\
\text { prato do cliente, trazida pelo servidor } \\
\text { 2. O servidor coloca o prato na frente do } \\
\text { cliente }\end{array}$ & $\begin{array}{l}\text { O prato com o alimento } \\
\text { é colocado na frente do } \\
\text { comensal pelo seu lado } \\
\text { direito. O servidor usa } \\
\text { sua mão direita para tal }\end{array}$ & $\begin{array}{l}\text { Pela direita, se posicionando atrás do cliente, sem } \\
\text { cruzar sua frente. Dessa forma, o servidor usa sua } \\
\text { mão predominante (direita) e o comensal recebe o } \\
\text { prato, também, do seu lado predominante }\end{array}$ & $\begin{array}{l}\text { Pode se usar o cloche, para co- } \\
\text { brir o prato, refinar o serviço, } \\
\text { causando expectativa e surpresa } \\
\text { (chamado de serviço à la cloche) }\end{array}$ \\
\hline
\end{tabular}

Fonte: autores (2016) 


\section{CONSIDERAÇÕES FINAIS}

Esse estudo trata de uma análise exploratória e teórica da tipologia clássica dos serviços e, consequentemente, como em qualquer pesquisa científica, carece de aprofundamento. Portanto, a proposta realizada aqui é um início da discussão e da pesquisa científica sobre o tema proposto. Em um primeiro passo para esse aprofundamento, deve-se estender o painel de validação a mais profissionais e acadêmicos da gastronomia, buscando validar ou refutar as propostas aqui presentes e/ou modificá-las de acordo com os dados empíricos de uma futura pesquisa. Deve-se, também, averiguar mercadologicamente a execução dos tipos de serviços completos. Em uma futura pesquisa de campo com os principais empreendimentos do gênero, buscar-se-á revelar como esses serviços estão sendo empregado atualmente, procurando, dessa forma, a validação dessa proposta por diversos empreendedores.

Adotando o significado do consumo de serviços a partir da natureza (ordinária/extraordinária) da experiência vivida pelo consumidor, os resultados aqui obtidos visam a experiência extraordinária em gastronomia. Esse significado "enfatiza a participação do consumidor na produção de experiências de consumo em restaurantes, pois é ele que irá interpretar os serviços disponibilizados pelo mercado, embora o sistema de oferta proposto pelas empresas influencie a sua interpretação sobre os produtos e serviços consumidos" (Barbosa, p. 84, 2006). Sendo assim, procura-se com esse estudo sintonizar cliente e empreendedor.

O processo de padronização visando a qualidade é lento e gradual. Portanto, para que isso ocorra pode-se utilizar o processo chamado de recuperação de serviços, o qual "é definido como as atitudes tomadas por uma empresa quando ocorrem falhas no processo de prestação de serviços [...] sistematizar as atividades de recuperação é o caminho encontrado pelas organizações que conhecem seus processos e sabem que, pelas características que existem nos sistemas de prestação de serviço, falhas irão ocorrer e que é necessário estar à frente destes acontecimentos para atuar de forma a não perder a confiança do cliente" (Slack et al., 1996 apud Oliveira, p. 26, 2002). Isso visa, em princípio, a adequação da brigada de trabalho às sugestões de padronizações expostas nesse estudo e em outros futuros. O que se percebe na restauração é uma falta de padronização e o consequente desentendimento entre servidor e servido. Os autores desse presente estudo preconizam que o foco desse tipo de serviço deve ser sempre o cliente. Portanto, afim de padronizar a execução desse tipo de serviço, deve-se sempre executá-lo pela direta do cliente e o servidor deve colocar o prato na frente do mesmo com a mão direita, posicionando-se atrás dele. Os servidores canhotos devem se adequar à essa regra e não o oposto, cabendo ao empreendedor treinar e adequar a brigada de trabalho à essa padronização.

Sob a ótica do presente estudo, o campo de pesquisa que mais carece de aprofundamento é o ato do mise en place. Um estudo sobre esse tema, sob a mesma ótica do presente, faz-se necessário para complementar a padronização dos serviços clássicos. Pois, sem o mise 
em place, a prestação desses serviços permanece inacabada. Consequentemente, em um terceiro momento, pode-se criar um modelo/fluxograma da operação completa com caráter prático e aplicável, tendo o modelo de recuperação de serviços, pois esse "é, em geral, representado por modelos constituídos de etapas que mostram os passos a serem seguidos no caso de uma falha" (Oliveira, p. 28, 2002). No entanto, "a comparação com os modelos apresentados na literatura revelou que não existe nenhum modelo que se ajuste aos modelos obtidos para [...] restaurante à la carte" (Tinoco, 2006). Faz-se necessário então a criação ou adaptação de um modelo especifico para a avaliação da qualidade dos serviços gastronômicos em estabelecimentos de serviço completo que utilizem a tipologia clássica de serviços ao cliente.

Espera-se que o presente estudo tenha elucidado algumas dúvidas comumente percebidas na restauração em gastronomia, sintetizando o conhecimento cientifico ao empírico e validando esse através de um painel avaliador, visando a melhora da qualidade da experiência gastronômica. As propostas elencadas aqui, visam abrir a discussão e pesquisa sobre o tema e apontar os futuros campos de pesquisa, e não as findar somente a esse estudo.

\section{REFERÊNCIAS}

Ameer, I. (2014). Satisfaction- A behavioral perspective on consumer: Review, criticism and contribution. International Journal of Research Studies in Management, 3(1), 75-82.

Arduser, L. \& Brown, D. (2005). The Waiter \& Waitress and Wait Staff Training Handbook: A Complete Guide to the Proper Steps in Service for Food \& Beverage Employees. Ocala: Atlantic Publishing Group Inc.

Booklist Online. (2010). Booklist Review. Larousse Gastronomique: The World's Greatest Culinary Encyclopedia. American Library Association. Disponível em: http://www.booklistonline.com/LarousseGastronomique-The-World-s-Greatest-Culinary-Encyclopedia-/pid=3785505. Acessado em: 10 de abril de 2016.

Bressan, S. J. (2008). Fundamentos das Ciências Sociais. Ijuí: UNIJUÍ.

Cândido, I. (2010). Restaurante - administração e operacionalização. Caxias do Sul: EDUCS.

Chateau de Versailles. (2016). Restoration of the Queen's Salon du Grand Couvert. Disponível em http://en.chateauversailles.fr/news-/events/life-of-the-estate/restoration-of-the-queens-salon-dugrand-couvert. Acessado em: 28 de junho de 2016.

Dahmer, S. J., \& Kahl, K. W. (2009). Restaurant service basics. Hoboken: John Wiley \& Sons, Inc. Eleutério, H. (2014). Serviço de alimentação e bebidas. São Paulo: Érica.

Gonçalves, J. A. T. (2008). Metodologia de pesquisa. Critérios para delimitação do tema. Disponível em: http://metodologiadapesquisa.blogspot.com.br/2008/10/delimitao-do-tema.html. Acessado em: 05 de março de 2016. 
Johns, N. \& Pine, R. (2002). Consumer Behaviour in the Food Service Industry: A Review. Hospitality Management, 21, 119-134.

Kotschevar, L. H., \& Luciani, V. (2007). Presenting service: the ultimate guide for the foodservice professional. Hoboken: John Wiley \& Sons, Inc.

Krause, R. W. (2014). Aspectos determinantes na percepção da qualidade dos serviços na experiência gastronômica turística. Caderno Virtual de Turismo. Rio de Janeiro, 14(1), 19-33.

Krause, R. W. \& Bahls, A. A. D. S. M. (2016). A gastronomia como fator de influência na escolha de destinações turísticas - base de estudo balneário Camboriú (SC-Brasil). PASOS. Revista de Turismo y Patrimonio Cultural, 14(2), 433-446.

Lang, J. H. (Ed.). The Larousse Gastronomique: The New American Edition os the World's Greatest Culinary Encyclopedia. New York: Librarie Larousse, 1995.

Macionis, J. J., \& Gerber, L. M. (2011). Sociology. Pearson Prentice Hall.

Marconi, M. D. A. \& Lakatos, E. M. (2011). Metodologia Científica. 6. ed. São Paulo: Atlas.

Martinage, B. M. \& Martinage, C. (2013). Associate Handbook: Fine Dining Standards (Certification Codes Sold Separately edition). CreateSpace Independent Publishing Platform.

Martins, G. D. A. (2009). Metodologia da investigação científica para ciências sociais aplicadas. São Paulo: Editora Atlas.

Oliveira, K. (2002). Recuperação de serviços no processo de atendimento em restaurante: estudo de caso em Porto Alegre. 91 f. Dissertação (Mestrado) - Curso de Mestrado em Engenharia, Universidade Federal do Rio Grande do Sul, Porto Alegre.

Payne-Palacia, J. \& Theis, M. (2012). Foodservice Management: Principles and Practices. Pearson Education, Inc.

Scarpato, R. (2004). Gastronomy as a Tourist Product: the Perspective of Gastronomy Studies. Tourism and Gastronomy, p. 51-69. U.K.: Routledge.

Schneider, S. \& Schmitt, C. J. (1998). O uso do método comparativo nas ciências sociais. Cadernos de Sociologia, p. 49-87.

The Culinary Institute of America - CIA. (2009). Remarkable Service: A Guide to Winning and Keeping Customers for Servers, Managers, and Restaurant Owners. John Wiley \& Sons.

Tinoco, M. A. C. (2006). Proposta de modelos de satisfação dos consumidores de serviços. 119 f. Dissertação (Mestrado) - Curso de Mestrado em Engenharia, Universidade Federal do Rio Grande do Sul, Porto Alegre.

Vosgerau, D. S. R. \& Romanowski, J. P. (2014). Estudos de revisão: implicações conceituais e metodológicas. Revista Diálogo Educacional, Curitiba, 14(41), p. 165-189. 
Artigo recebido em: 23/02/2016. Artigo aprovado em: 11/08/2016.

\section{Rodolfo Wendhausen Krause}

Universidade do Vale do Itajaí (Univali) - Possui graduação em Engenharia Mecânica pela Universidade Federal de Santa Catarina (1982), graduação em Administração e Gerência pela Universidade do Estado de Santa Catarina (1981), mestrado em Turismo e Hotelaria pela Universidade do Vale do Itajaí (2001), doutorado em Turismo e Hotelaria (2007) e, um segundo, em Administração e Turismo pela Universidade do Vale do Itajaí (2011). Foi o responsável pelo projeto e a implantação do curso de Gastronomia da Univali, tendo sido seu coordenador no período de 1999 a 2010. Atualmente é professor permanente do Programa de Mestrado em Turismo e Hotelaria da Universidade do Vale do Itajaí. Tem experiência na área de Administração, no Turismo e na Restauração (Restaurantes, Bares e Similares), com ênfase em Planejamento, Gestão e Marketing na Restauração, atuando principalmente nos seguintes temas: qualidade, reestruturação, alimentos e bebidas, treinamento e implantação. Avaliador Ad hoc do Ministério da Educação. E-mail: rodolfo@univali.br

\section{Álvaro Augusto Dealcides Silveira Moutinho Bahls}

Universidade do Vale do Itajaí (Univali) - Graduado em Turismo e Hotelaria pela Universidade do Vale do Itajaí (2003), com estágio de conclusão do curso em Snowshoe Mountain Resort USA. Possui experiência profissional internacional, incluindo 04 temporadas de inverno em Resorts nos EUA. Ênfase foi dada à gastronomia e ao lazer e recreação (ensino do esqui), sendo este seu primeiro contato com a pedagogia. Atuou na área de intercâmbios universitários no exterior, através da Intercultural (com sede em Florianópolis), uma das mais tradicionais agências de intercâmbio do estado de Santa Catarina. Foi representante da mesma na UNIVALI, através da Agência Acadêmica de Turismo ACATUR. Em sua última temporada de inverno nos EUA teve a oportunidade de trabalhar em Vail CO, um dos grandes destinos de férias do país. A principal área de atuação foi artística, atuando como fotógrafo de esportes radicais e eventos particulares. Recentemente, residiu na Rep. Tcheca, na cidade de Cesky Krumlov (patrimônio histórico mundial da UNESCO) considerada uma das cidades medievais mais bem preservadas da Europa, onde administrou o Hostel 99, principal meio de hospedagem do gênero neste importante destino turístico. Foi professor de inglês do Centro de Cultura Anglo-Americana durante dois anos, sendo esse seu segundo contato com a pedagogia. O CCAA atua na área de ensino de línguas há mais de 50 anos. Conclui o curso de Mestrado em Turismo e Hotelaria (UNIVALI) em julho de 2015, com a dissertação intitulada HOSTELS: Proposta conceitual, análise socioespacial e panorama atual em Florianópolis (SC). Atualmente é doutorando em Turismo \& Hotelaria, Bolsista Integral da Coordenação de Aperfeiçoamento de Pessoal de Nível Superior e atua como editor do periódico internacional Applied Tourism (UNIVALI). E-mail: alvarobahls@edu.univali.br 